\title{
SYSTEM FOR RECYCLING OF WASTE AND SLUDGE FOR REDUCTION OF LANDFILL DISPOSAL OF MSW
}

\author{
Conny Rudin \\ SweConDa AB, Sweden
}

\section{Information about $\quad$ SweConDa $A B$}

\section{Business idea}

SweConDa $\mathrm{AB}$ will contribute towards a complete recycling as possible using the resources available in our household waste and sludge. Resources that either puts on deposit or used as fuel for energy plants. To recycle the resources means that metals and glass are separated and recycled, plastic separates and are used as premium fuel for energy and the part for compost, reducible material are separated for representing a premium environmental organic fertilizer for forestry, agricultural and gardening.

Using this method we attains a recycling degree of $95-97 \%$ from the incoming material, and this is of great importance not least for the coming generations. Appendix 1.

\section{Market}

The Market contains two parts

a) suppliers of household waste and sludge, slaughter waste etc.

b) buyers of the fertilizer.

The suppliers of household waste and sludge are primarily the municipalities. Other parts of the organic waste could come from industries as slaughter-houses, bakeries, provision producers etc. Both parts wants long time agreements in order to control investments and organization of the assortment and collection of the waste.

Buyers of the fertilizer are farmers, forestry's, gardens, garden centers and households.

SweConDa $\mathrm{AB}$ possesses permit from the authorities to receive up to 75.000 ton household waste, sludge, slaughter-house waste, chicken and swine-manure and other organic waste. The method to manage this material contains pre-assortment, quick-composting in a rotating mixing drum, post-assortment, post-composting and the representation of the organic fertilizer based upon the customers description or desire. 


\section{Business possibilities}

At the writing of this business plan contracts are written for deliveries of 20.000 tons household-waste, $27 \%$ of the total capacity. The deliveries can start the 1 of January 2000. It is possible for this supplier to increase the deliveries successively. Our plan is therefor to start the construction of the receiving-hall for pre-assortment. Plastic and metal will here be separated and the Organic waste will be wrapped up and transported to a near by mine (Yxhult). This material will be a part of the production of Organic fertilizer in 2001.

\section{Activity}

SweConDa AB co-operates with companies to guarantee the process. The technique concerns the whole process described under that head-line in the business-plan.

SweConDa $\mathrm{AB}$ has also a reserved ground area for purchase or rental. The owner is Kumla Municipality. The area is positioned in Kvarntorp that is the sight for a number of the companies involved in the Kvarntorps Kretsloppspark Economic Association.

\section{The Product}

The product, fertilizer, that becomes the result of the recycling-process will be adapted in its substance based upon the customers descriptions or desire.

\section{The Organic Fertilizer}

It is possible to construct it for long time as well as short time use depending on how rapid it dissolves how rapidly the construction of humus are desired.

For the forestry's will a long-time fertilizer be used, that contains a normal rate of nutrition is firm in compound and hard pressed together therefore in a pace that the plants are in need of nutrition. Can be spread at the same time as plantation, or from a helicopter.

In agriculture a short-time fertilizer will be used, it can contain a higher rate of nutrition, and be softer in its compound. It is designed to dissolve under the plants growth season. Normal agricultural-machines can be used for the spreading.

For parks, gardens and garden-centers a medium or long-time fertilizer will be used. It can contain various amount of nutrition and be rather firm in its compound. Its purpose is to slowly dissolve under a period of years and give nutrition continuously to the plants. Spreads at the same time as plantation or treatment of plants. This product can also be used in the home environment or in offices.

All products are nutrition-declared and the heavy-metals and other government regulated substances are below the prescribed limits.

\section{The Process}

In the production of Organic fertilizer we uses the Organic parts of the household-waste and add sludge. This must be performed in several steps to separate and control the material during the process. A process-description

Reception of household-waste from communities/companies and sludge from municipality cleaning-plant. Pre-assortment (plastic, metal, glass). 
Mixing-drum. After the pre-assortment waste and sludge are mixed in a rotating mixing drum for two up to three days and nights. The mix can be one part sludge and two parts of waste. This process gives compost through a microbiological process.

Post-assortment. When compost leaves the mixing-drum a second assortment takes place. All non-Organic material (smaller parts of plastic, glass, metal, batteries) and other pollution's assorts from the compost.

Post-composting. In the post-composting-hall the compost are stored under favorable conditions through controlled moisture and temperature. The compost are worked through by turning and air-conditioning.

Organic fertilizer. The compost is now hygienic and can be used as a Organic fertilizer. The Organic fertilizer can be delivered in a various amount of ways, loose-weave or soft alternative firm in component.

\section{Reject (materials that wont be compost)}

Glass Assorted glass is delivered to Svensk Glasåtervinning (Swedish Glass recycling)

Sheet-metal Assorted fractions of sheet-metals is delivered to metal recycling.

Plastic Assorted plaits is delivered to energy plants and used as fuel to create heat.

Battery etc. Batteries are classified as environmentally dangerous and are therefore delivered for destruction.

Others Deposit-materials is delivered for deposit, $3-5 \%$ of the received amount of waste.

Appendix 2.

The entire process is sealed which gives total control over particles and odor. The out coming air from the plant is cleaned through bio-filters. The bio-filter will be a so called Bio-Tower, particles and odor passes through scrubbers and water baths. In the top of the tower a "helicopter-fan" will be placed. The fan pressures the air high up the air stratums, eventually odors will therefore never reach ground-level.

\section{Customers}

The customers for our product Organic fertilizer can be separated into four different groups.

1. Forestry

2. Agriculture

3. Park and Gardening

4. Households

In forestry testing of the product has been performed. The result gives a highly improved growth during the first 5-6 years. The plant utilized the nutrition through the whole period. The test results shows between $25-100 \%$ better growth among the plants with Organic fertilizer compared to those in natural environment the last 6 years. The plants with Organic fertilizer also shows a higher survival rate. The Organic fertilizer increases the humus and stops the impoverish of the ground. This gives a greater and larger fauna. 
Within agriculture the Organic fertilizer primarily will be used for KRAV-growth. This group of agriculture's are increasing and are in need of a fertilizer to use on their farms. Testing will be performed on the Organic fertilizer by acknowledged professors to get the brand that is necessary for products used on KRAV-growth.

Park and gardening are in need of a long time term product free of odor and easily spread and storable. In this sector can also golf-courses be of big interest.

For households the product suits very well to be used in flower-beds, lawns, pots etc.

\title{
Competitor
}

The most of the competitors you have in artificial fertilizing. If we just look at the part of fattening and alimentary is the Organic Fertilizer a product of the nature and if we look at the artificial fertilizer that is a chemical product developed to getting a high growing value during a short time. From the farms we have big problems with spilling out the artificial fertilizer to the seas and other watercourses.

Organic fertilizer has an another purpose and it means that you have a long time value function, don't spill out anything to the seas and it is still there as humus. The Organic fertilizer comes from vegetable and animal waste and it will be a good fertilizer for, What we call in Sweden, KRAV-growth special for grain and vegetables consumers.

The usual consumer of Organic fertilizer can get the product in different ways. Big pack, small pack and so on. These packages you can easy have in your garage and it does not smell. Your Organic fertilizer is just as you want it.

\section{The market}

SweConDa will at first go to the existing market for gardens and distributors for the KRAVgrowth. These contacts we already have been taken and we can see the interest. Other contacts we have been taken is with forest companies. They will need the Organic fertilizer for the new plants to give them a good start and get more of the plants to live and grow faster the first 5-6 years.

\section{Contacts and network}

Good contacts we have locally inside the Kvarntorp Recycling Park or Kvarntorp Ecocycle Centre, there SweConDa is one of the members. As regards organization, Kvarntorp Ecocycle Centre functions as an economic association, and its members comprise local authorities and companies in the county of Örebro. Thanks to our co-operation inside SweConDa we have also good contacts with supplier of machine equipment's. At the same time we have also good contacts in the business of forests and agricultural.

\author{
For SweConDa AB \\ September 1999 \\ Conny Rudin \\ Manager
}




\section{Recycling household waste and sludge}

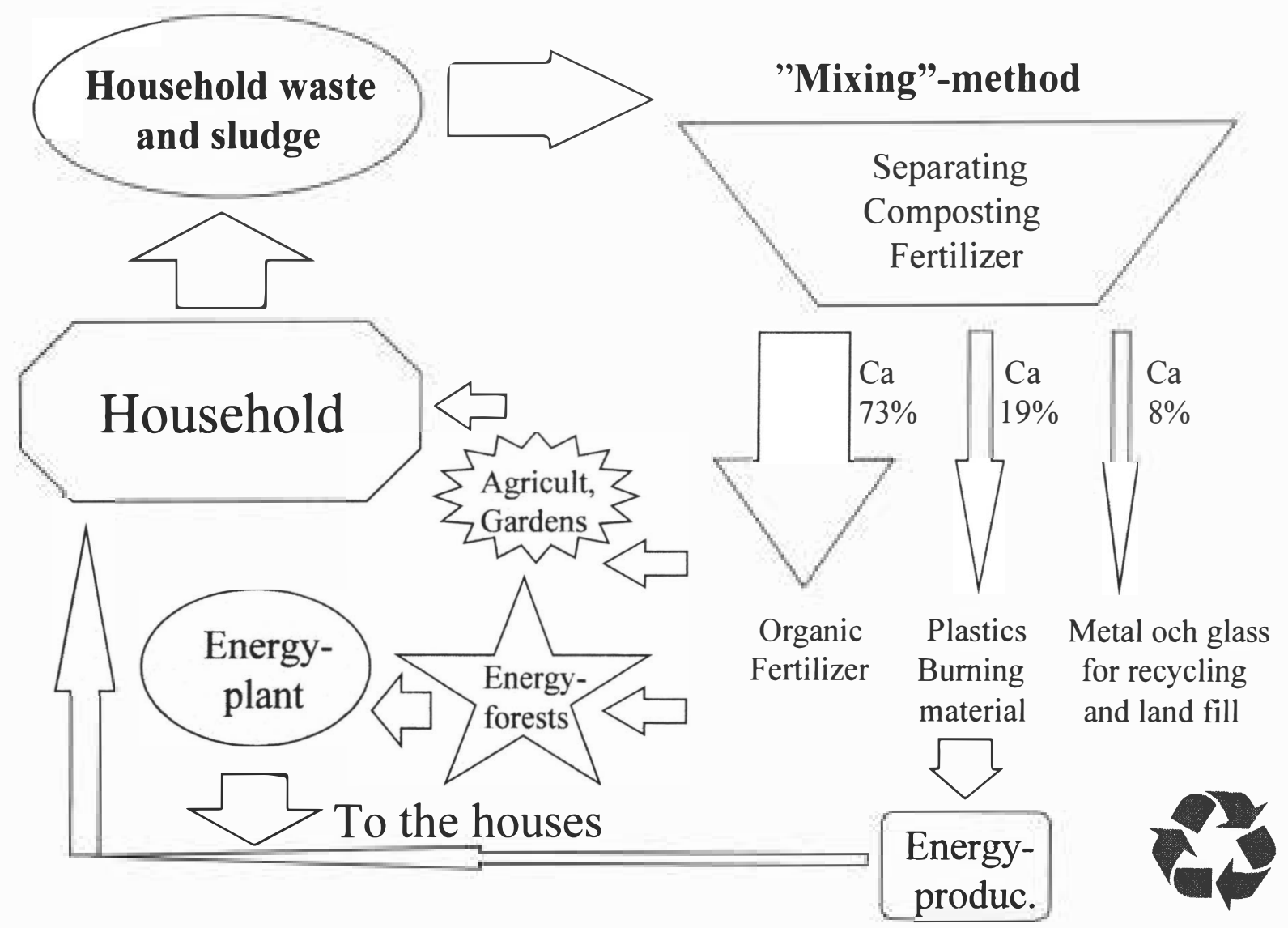




\section{Composting process}

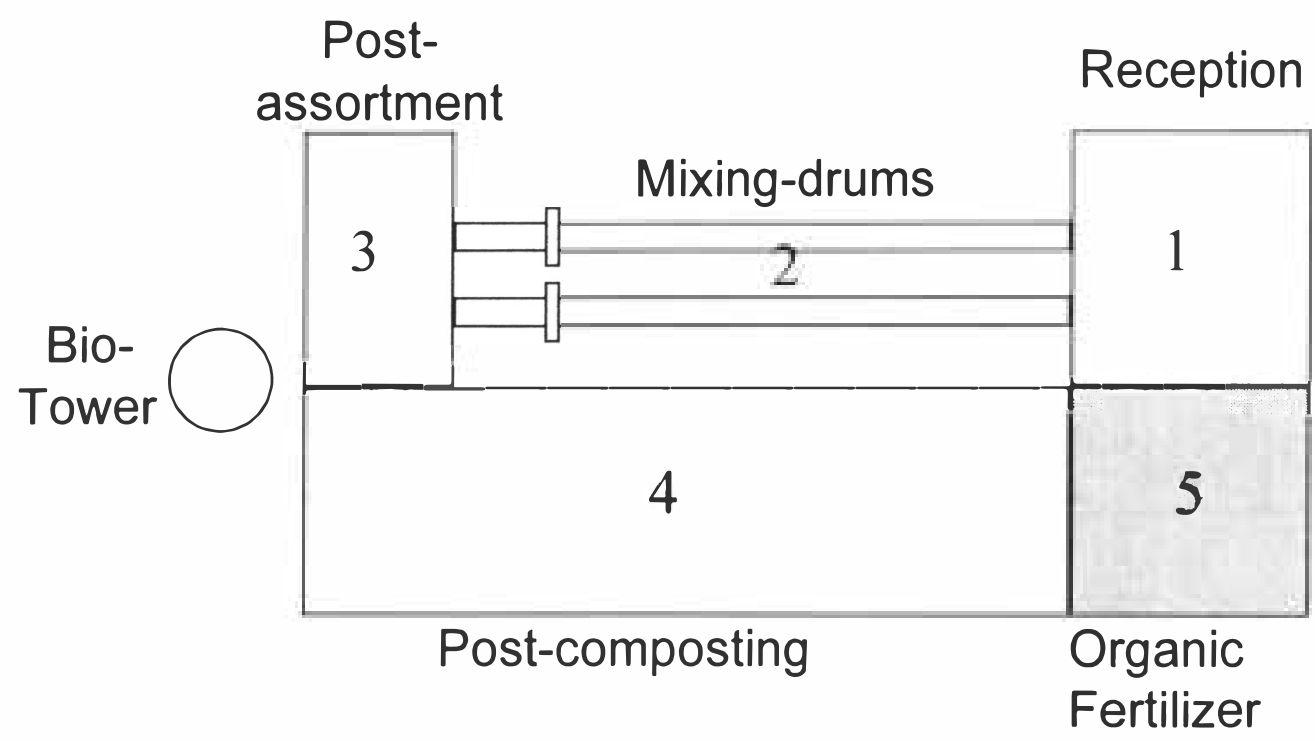

1 Reception of household waste, sludge. Pre-assorment plastic, metal, glass

2 The Organic material are mixed in a rotating mixing-drum

3 Post-assortmen of plastic, metal, glass, batteries

4 Post-composting for 3-6 weeks

5 Making Organic Fertilizer in package for the customers 